TRANS $\cdot$ NÚM. II $\cdot 2007$

El siguiente artículo presenta la trayectoria y la situación actual

DOSSIER $\cdot 31-43$ en España de los dos servicios de accesibilidad a los medios más extendidos y desarrollados: el subtitulado para personas sordas y la audiodescripción. Se presentan sus origenes, su evolución y las tendencias de futuro. Se repasan, asi mismo, las nuevas normas que regularán el sector audiovisual, especialmente alli donde se hace mención explícita a la accesibilidad, y las guías de buenas prácticas profesionales, necesarias para garantizar la homogeneidad en la prestación de los servicios. Se analizan también las implicaciones económicas y operativas que supone para la industria de la radiodifusión el cumplimiento de estas nuevas obligaciones. El artículo finaliza proponiendo una serie de acciones y recomendaciones para alcanzar la accesibilidad audiovisual y la sensibilización social hacia estos servicios tan necesarios, que aunque ya están disponibles en la actualidad, deberán estarlo en mayor medida durante el periodo de transición de la televisión analógica a la digital y tras el apagado de las señales analógicas en 2010.

PALABRAS CLAVE: Accesibilidad, audiodescripción, subtitulado para sordos, traducción audiovisual.

\title{
Visión histórica de la accesibilidad en los medios en España
}

PILAR ORERo,

Universidad Autónoma de Barcelona

Ana María Pereira,

Universidad de Vigo

FRANCISCO UTRAY,

Universidad Carlos III de Madrid
The aim of the following article is to portray the state of the art in Spain of the two most popular media accessible modalities: audio description and subtitling for the deaf and hard of hearing. The article traces its origin and development up to the present time. Standards and laws are also examined, and there is an analysis of the economic and operative implications of media accessibility, since it does not follow traditional economic parameters. The article finishes proposing the many actions which can be taken in order to reach full media accessibility and to raise popular awareness towards these new services which are now available, and will be increasingly so with the shift from analogous to digital broadcasting.

KEY WORDS: Accessibility, Audio description, Subtitling for deaf and hard of hearing, Audiovisual translation. 


\section{INTRODUCCIÓN}

La profunda transformación que está teniendo lugar en los medios de comunicación audiovisuales en Europa debe beneficiar a todos y particularmente al creciente número de personas con necesidades especiales como es el caso de todas aquellas con discapacidad sensorial. En Europa no sólo se está experimentando un aumento en la población de personas mayores, sino que hay que tomar también en consideración el incremento de la expectativa de vida'; ambos aspectos contribuyen al aumento progresivo de la cifra de personas con discapacidad sensorial y dificultades para el acceso a la comunicación audiovisual. Este artículo presenta una visión general, centrada en España, de los servicios de accesibilidad audiovisual más extendidos y desarrollados: el subtitulado para personas sordas (sPs) y la audiodescripción (AD). Tras una introducción en la que se definen estos dos servicios y sus orígenes, el artículo presenta las leyes y normas que los regulan y las implicaciones económicas y operativas que tiene su implantación masiva en los medios de comunicación audiovisual. E1 artículo finaliza con las iniciativas que se han puesto en marcha para la promoción y difusión de la accesibilidad audiovisual en España y los símbolos gráficos e iconos recomendados para señalizar la presencia de dichos servicios.

\section{DEFINICIONES DE AUDIODESCRIPCIÓN Y SUBTITULADO PARA SORDOS}

Uno de los factores más importantes al hablar de accesibilidad en los medios es el hecho de que España es tradicionalmente un país doblador. Esta característica influye directamente en

I El crecimiento anual del envejecimiento de la población en Europa se estima en torno o por encima del r\%. Fuente: Eurostat 2002. las posibilidades de accesibilidad que se ofrecen. Si ponemos por ejemplo a nuestro vecino Portugal, donde los programas que no son de producción propia están subtitulados, ¿querrá esto decir que la audiodescripción estará mucho más limitada que en nuestro país donde la gran mayoría de programas están doblados al castellano o a cualquiera de las lenguas oficiales? Esta característica de ser país doblador también influirá directamente en los perfiles laborales así como en la metodología de trabajo (Orero en prensa a).

Cronológicamente, la primera definición de AD en España la ofrece Navarrete, uno de los descriptores que trabaja desde hace años para la once y que la define como «el arte de hablar en imágenes» (I997:7I). Por su parte, Vidal (2004:30) dice que la $\mathrm{AD}$ «simplemente intenta explicar la acción de una obra, programa de TV o película de tal forma que la persona ciega pueda seguir el desarrollo del argumento de la mejor forma posible». En tercer lugar, nos encontramos con la siguiente definición que se ofrece en la Norma UNE I53O2O de AD (AENOR, 2005:4):

Servicio de apoyo a la comunicación que consiste en el conjunto de técnicas y habilidades aplicadas, con objeto de compensar la carencia de captación de la parte visual contenida en cualquier tipo de mensaje, suministrando una adecuada información sonora que la traduce o explica, de manera que el posible receptor discapacitado visual perciba dicho mensaje como un todo armónico y de la forma más parecida a como lo percibe una persona que ve.

En lo que respecta al sps, éste se podría definir como una modalidad de trasvase entre modos (de oral a escrito) y, en ocasiones, entre lenguas. Consiste en presentar en pantalla un texto escrito que ofrece un recuento semántico de lo que se emite en el programa en cuestión, pero no sólo de lo que se dice, cómo se 
dice (énfasis, tono de voz, acentos e idiomas extranjeros, ruidos de la voz) y quién lo dice sino también de lo que se oye (música y ruidos ambientales) y de los elementos discursivos que aparecen en la imagen (cartas, leyendas, carteles, etc.) (Pereira, 2005:I62). A diferencia del subtitulado que consumen los receptores que no presentan déficit auditivo, el dirigido a los espectadores sordos se articula únicamente en torno a dos componentes: los subtítulos y la imagen que los acompaña. Estos dos elementos, junto con la naturaleza y el ritmo de lectura del receptor, definen las características diferenciales del subtitulado para sordos, que en España son un millón de personas (Ibíd.).

Aunque la norma UNE 153010 de subtitulado para sordos a través del teletexto (AENOR, 2003) no ofrece una definición de esta modalidad de trasvase audiovisual, sí la encontramos definida como sigue en el documento emanado del grupo de trabajo «Foro Técnico de la Tv Digital» (2005:IO): «Servicio de apoyo a la comunicación que muestra en pantalla, mediante texto y gráficos, los discursos orales, la información suprasegmental y los efectos sonoros que se producen en cualquier obra audiovisual».

La nueva Ley General del Audiovisual, que se encuentra en fase de debate parlamentario, define el sPS y la AD como servicios: «Se entiende por subtitulado, un resumen escrito de los diálogos, músicas y efectos de sonido, presentado en pantalla de forma simultánea al sonido, visible a voluntad del telespectador» $\mathrm{y}$ «Se entiende por audiodescripción la banda de sonido inde-

2 Grupo de trabajo promovido por la «Secretaria de Estado de Telecomunicaciones y para la sociedad de la Información», Ministerio de Industria Comercio y Turismo, cuyo principal objetivo es disponer de un foro donde tratar los aspectos técnicos y donde se impulsen iniciativas para el desarrollo e implantación de la TV digital, contemplando de manera global todos los aspectos y tecnologías. pendiente que puede ser seleccionada por el telespectador y que describe los personajes, los decorados y las acciones clave con objeto de hacer inteligible a personas ciegas el contexto en el que se desarrollan los diálogos» (Ministerio de Industria, Turismo y Comercio, 2005: 52).

\section{BREVE HISTORIA DE LA}

AUDIODESCRIPCIÓN Y DEL SUBTITULADO PARA SORDOS

En el caso de la audiodescripción de material audiovisual grabado, España es pionera en este sistema ya que las primeras AD las ofreció el periodista Gerardo Esteban por radio en los años posteriores a la Guerra Civil. Jorge Arandes, quien durante años fue director de toda la red de programas de RNE en Madrid y director gerente de RTVE en Barcelona, explica en una entrevista publicada en JosTrans (Orero, 2007) y en el programa de radio RNE «Un día Cualquiera» (Arandes, 2006) cómo Radio Barcelona, a través de Gerardo Esteban, fue la primera emisora en hacer AD de películas, que se narraban en directo desde los cines:

La película ya estaba doblada y sólo había que poner comentarios a la banda [...] Los diálogos siempre se respetaban, las AD las pagaban las empresas distribuidoras [...] La primera película fue Gilda (1946) [...] La segunda fue Mi mula Francis (I950) [...] Estas dos películas se hicieron la misma semana $\mathrm{y}$, después, se hacía una cada semana; la tercera fue María Antonieta (1938) [...], que se retransmitió desde el cine Tívoli de Barcelona. Todas [...] eran películas de actualidad que se estaban proyectando.

Sin embargo, estas retransmisiones molestaban al público, de manera que, Arandes sigue explicando (Ibíd.), las distribuidoras habilitaron pequeñas salas de proyección para que los descriptores trabajaran más cómodos; seguían haciendo su trabajo en directo aunque no tan improvisado: 
Primero se veía la película dos veces en una misma tarde [...] Mientras se proyectaba yo iba tomando notas, sobre todo de aquellos cambios de secuencia más rápidos [...] y me iba haciendo un guión [...] Cuando en la cabina ya lo tenían todo listo para comenzar la proyección, yo hacía una pequeña introducción «señores hoy estamos aquí en la sala de Fox Film para retransmitir la película tal con Carmen Miranda y esperamos que les guste porque es una película de tal estilo». No se hacía un resumen del guión, lo que sí que se hacía era dar el nombre de los actores de doblaje [...] porque el interés del oyente no es que fuese Gary Cooper sino quién era el que hablaba como Gary Cooper. A veces, había problemas para que los estudios de doblaje me dieran todos los nombres, pero de los dobladores principales sí. Eso es lo que decía como introducción, luego tocaba un timbre y comenzaba la proyección. Y entonces yo decía «Columbia Pictures presenta tal, tal, tal y cual» y luego iba siguiendo el guión con las notas que había tomado y lo que estaba viendo [...] El lenguaje que utilizaba en las descripciones era muy escueto, yo describía lo que pasaba, no importa que fuera una película romántica o de espías. Yo me limitaba a describir lo que veía: fulano de tal se acerca a Elisabet. Ella le mira con cara compungida y espera que reaccione por lo que ha hecho, se acerca y la besa.

Además de las películas, este descriptor cuenta que también se retransmitían las óperas:

Yo empecé a retransmitir óperas desde el Liceo en RNE en los años 5o. Todas las óperas siempre se retransmitían por radio. Primero a Barcelona por Radio Nacional de Barcelona y más tarde, cuando se inauguró la frecuencia modulada, se ofrecieron a través de FM a toda España. La primera vez que se hizo una parte de una ópera por TVE también la hice yo. Fue Tosca de Puccini con Renata Tebaldi.

Mateos Miguélez (2005), cuando expone

los orígenes de la AD específicamente dirigida a personas deficientes visuales, los sitúa en la ONCE y los fecha un poco más tarde, en r993. La ONCE tiene un sistema de distribución entre sus afiliados «que comenzó con cuatro películas en vHs y en 1997 había aumentado 25 películas por año» (ONCE I997, citado en Mateos Miguélez, 2005:39). La ONCE bautizó el sistema de audiodescripción como Audesc y en el artículo de Hernández Bartolomé y Mendiluce Cabrera (2004) se describe sus orígenes y el desarrollo tanto en grabado como en el cine y festivales de cine.

El 22 de febrero de 1995 el canal de TV autonómico andaluz Canal Sur comenzó a emitir AD y hasta finales de 1996 emitió 76 películas. La recepción de la $\mathrm{AD}$ se hacía por radio en la cadena Canal Sur Radio. Más tarde, en octubre de I997, comenzó una nueva iniciativa llamada Cine para Todos, que ofrecía AD y sps y duró hasta diciembre de 200I. En total se ofrecieron I32 películas y, mientras que al comienzo eran los domingos, más tarde el programa pasó a los sábados. El subtítulo se ofrecía por teletexto y, como ya hemos dicho, la AD por Canal Sur Radio. ${ }^{3}$

En 1999, el canal autonómico catalán TV3 comenzó a emitir la serie Plats Brut con AD. En este caso, la recepción de AD era optativa por medio del sistema NICAM DUAL estéreo. El trabajo de AD se realizó en colaboración con la ONCE y, desde entonces, TV3 también ha emitido audiodescritas las series: Majoria Absoluta y L'un per l'altre.

Mateos Miguélez (2005:34) explica cómo el director general de RTVE en el Parlamento, el día 28 de mayo de 2003 , informó de que se ofre-

3 Queremos agradecer a Fernando Mancha de la empresa Mundovisión (Sevilla) toda la información referente a la audiodescripción en Canal Sur. 
cería el servicio de AD en el programa Cine de Oro y que había la intención de que este servicio se extendiera a otros programas si había presupuesto (RTVE, 2003a).

En 2002 RTVE, junto con la editorial BRB Internacional y la ONCE, produjeron una serie de dibujos animados para niños llamada Nicolás en la que el protagonista es un niño ciego y donde la $\mathrm{AD}$, que se ofrece en abierto, formó parte del proceso de producción. En la actualidad la RTVE ofrece algunas películas audiodescritas en el programa Cine de Barrio.

Mateos Miguélez (2005:36) asegura que los programas con AD son casos aislados y que, por ejemplo, el programa Guías Pilot tuvo AD en el capítulo titulado «China Central» (3 de septiembre de 2003) (RTVE, 2003b) así como la película Las juergas del señorito (I4 de enero de 2004) (RTVE, 2005).

Aunque los cines españoles no están equipados con DTS o Dolby, que son los sistemas que permiten la exhibición de películas accesibles en cerrado (es decir, que en una misma sesión podría asistir una persona que quisiera escuchar la AD, así como otra que quisiera leer sps junto con el resto de espectadores), en ocasiones, se ofrecen sesiones audiodescritas en abierto, como son por ejemplo las que ofrece la Asociación Catalana de Ciegos y Disminuidos Visuales (ACC).

En el caso de la opera, el Gran Teatro del Liceo de Barcelona, tras ofrecer AD en las temporadas de 2004/5 y 2005/6 (Matamala, 2005 y Orero, en prensa b) a cargo de las ya mencionadas asociaciones $\mathrm{ACC}$ y ONCE 4 , en la temporada 2006/7 ofrecerá AD de forma profesional, independientemente de las asociaciones. Algunos teatros, como el Teatre LLiure de Barcelona,

\footnotetext{
4 Un dato curioso es que la misma opera se ofrecía audiodescrita dos veces, una por cada asociación.
}

el Teatre Nacional de Catalunya o el Teatre Borrás ofrecen AD de forma regular en asociación con la ONCE.

El primer DVD comercial en España con banda de AD fue la serie de TV3 ya mencionada Plats Bruts (2003). Tres años más tarde y en castellano, la película de Woody Allen Match Point y la tercera entrega Torrente, de Santiago Segura, han salido al mercado de DVD con AD, SPS y un menú interactivo con audio-navegación.

En España, los primeros subtítulos para sordos los emitió en 1990 la corporación catalana de televisión CCRTV ${ }^{5}$ y, unos meses después, se sumó a esta práctica TVE ${ }^{6}$. Poco a poco, el resto de cadenas de televisión del Estado comenzaron a ofrecer este servicio. Pardina (1998 y 200o, en Méndez Brage, 2002:53-66) ofrece un resumen del estado de esta realidad hasta 2000 , Pereira (2005) añade nuevos datos de los dos años siguientes y, en el presente artículo, actualizamos la información a partir de esa última fecha.

Telecinco empezó a subtitular para el receptor sordo a finales de $1997 \mathrm{y}$ ha ido aumentando progresivamente el número de horas subtituladas, de manera que ha pasado de 700 en 1998 a 2.367 en 2005. Ofrece subtitulado todos los días, en diversas fran-

\footnotetext{
5 Esta cadena, pionera en subtitulado para sordos en España, ha aumentado considerablemente el número de horas subtituladas: de 400 en 1997 a más de 6.086 en 2005. Canal Sur emitió en 2004 unas I950 horas subtituladas para sordos, dato que la sitúa en segundo lugar entre las cadenas autonómicas, seguida de la cadena valenciana RTVv, de la madrileña Telemadrid y, finalmente, de la vasca Euskal Televista.

6 Esta cadena pública ha ido incrementando el número de horas subtituladas para sordos: en 1997 ofrecía 400 horas, mientras que en 2005 ascendieron a 6.869 entre TVEI (2.380), La 2 (3.052) y Canal Internacional (I.443). Su servicio de subtitulado cuenta con su propio libro de estilo, elaborado a partir de la experiencia del equipo de subtituladores y del de las cadenas que les sirvieron como modelos, la BBC y la RAI.
} 
Tabla r: Horas de subtitulado para sordos por cadenas y años. Fuente: Centro español de subtitulado y audiodescripción (CESyA)

36

\begin{tabular}{|l|l|l|l|l|l|l|l|l|}
\cline { 2 - 9 } \multicolumn{1}{c|}{} & I998 & I999 & 2000 & $200 \mathrm{I}$ & 2002 & 2003 & 2004 & 2005 \\
\hline RTVE & 460 & 550 & 848 & I.I46 & I.446 & 3.300 & 5.028 & 6.869 \\
\hline TVC & 700 & I.000 & 2.000 & 3.100 & 4.165 & $4.72 \mathrm{I}$ & 5.737 & 6.086 \\
\hline Antena 3 & & & I.44I & 3.058 & 2.900 & $2.69 \mathrm{I}$ & 2.380 & 2.868 \\
\hline Telecinco & & I.500 & I.700 & 2.000 & 2.300 & 2.500 & 2.370 & 2.367 \\
\hline Canal Sur & 25 & I77 & 329 & 485 & 636 & I.324 & I.878 & 2.260 \\
\hline RTVV & & & & & 465 & I.I85 & I.408 & I.4IO \\
\hline Telemadrid & & & & & I.I35 & I.358 & I.354 & I.373 \\
\hline ETB & & 380 & 390 & 396 & 400 & 405 & 470 & 494 \\
\hline
\end{tabular}

jas horarias y para todo tipo de emisiones. La otra cadena privada, Antena3, inauguró su servicio de subtitulado en abril de 2000 . En un principio, su objetivo era subtitular 28 horas semanales en horario de máxima audiencia; en el 2005 emitió 2.868 horas de programación subtitulada entre series de producción propia y extranjera, concursos, películas, etc.

En la tabla I se despliega el creciente número de horas de subtitulado para sordos desde 1998 hasta 2005 , tanto en las cadenas estatales como en las autonómicas.

Por lo que respecta a la televisión de pago, Cartoon Network ha emitido, desde abril de 2000, algunos de sus programas con subtítulos para sordos y Disney Channel comenzó, el 2 de noviembre de 2003, la emisión de una selección de programas que incluían subtítulos para este colectivo. En ambos casos los subtítulos se insertan en el intervalo vertical de la señal de video $^{7}$ de la cinta digital, de forma que la sincronización entre los subtítulos y la imagen es óptima. El operador de satélite Digital Plus ha proporcionado a estos dos canales la infraestructura tecnológica necesaria para emitir subtítulos digitales a los que se accede a través del mando a distancia del receptor digital (Utray, 2005:357).

Además del subtitulado que ofrecen las distintas cadenas de televisión, el colectivo de sordos de nuestro país cuenta con la Videoteca subtitulada para personas sordas, iniciativa de FIAPas (Confederación española de padres y amigos de los sordos) y financiada desde I993 por el Ministerio de Trabajo y Asuntos Sociales. Este proyecto permite a las personas con problemas de audición acceder al cine a través del video doméstico desde sus hogares o asociaciones. Las películas se ofrecen dobladas al castellano y con sps en esta lengua con el fin de que las familias integradas por sordos y oyentes puedan disfrutar de esta actividad en compañía. Los filmes son de género variado y

7 En el Intervalo vertical (VBI Vertical Blanking Interval) es un espacio de la señal de video donde se puede insertar información de teletexto y de subtítulos. 
están dirigidos a todo tipo de público (infantil, juvenil y adultos). Ya se han distribuido más de 300 títulos entre las asociaciones y centros a los que asisten las personas sordas y que han solicitado su incorporación al programa. Participan en esta iniciativa casi doscientas entidades ubicadas en todas las provincias españolas (FIAPAS, 200I).

A diferencia de lo que veíamos que sucede con la $\mathrm{AD}$, las personas con déficit auditivo en España pueden comprar desde hace años (Almodóvar, 1990: Átame) filmes que incluyen subtítulos específicos para ellos.

\section{LEYES Y NORMAS}

En los últimos años se han dado una serie de pasos que nos permiten apreciar cómo la sociedad cada vez es más sensible a sus miembros con discapacidades sensoriales. Así, en junio de 200I ( $B O E$, Io de julio de 200I) se aprueba La Ley de Fomento y Promoción de la Cinematografía y el Sector Audiovisual, en la que se incentiva con subvenciones públicas a cualquier obra cinematográfica que incorpore AD y sPs.

Poco después, en mayo de 2002, los responsables de subtitulado para sordos de los canales privados Telecinco y Antena 3 pidieron al Gobierno una nueva ley que regulase la accesibilidad a los medios de comunicación y, en especial, a la televisión y que contribuyese a la investigación tecnológica en ese ámbito. Así, surge la Ley general del audiovisual con el objetivo de refundir las normas vigentes, adaptarlas al contexto tecnológico y social y regular el régimen jurídico de la radio y la televisión. Por lo que respecta a la accesibilidad, el artículo 62 establece la obligatoriedad de facilitar el acceso de las personas con discapacidades a la programación televisiva mediante sps, lenguaje de signos y $\mathrm{AD}^{8}$. Asi- mismo, se expone el calendario y porcentaje de material accesible que han de emitir los operadores del servicio público, los titulares de una licencia nacional y los titulares de los restantes canales de televisión con ámbito de cobertura nacional si su audiencia sobrepasa el diez por ciento de la audiencia potencial en su ámbito de cobertura9 ${ }^{9}$ (Utray, 2006:253). En la tabla 2 se muestra el calendario de implementación de los servicios de accesibilidad en la televisión española.

Con respecto a los códigos profesionales de buenas prácticas, en 2003, el Ministerio de Trabajo se hizo eco de las continuas peticiones de las personas sordas, que demandaban la elaboración de un criterio único para los subtítulos de los teletextos de las diversas cadenas de televisión, y encargó la redacción de una norma que regulase el subtitulado para sordos. Surgió así la norma UNE I530ro, Subtitulado para personas sordas y personas con discapacidad auditiva. Subtitulado a través del teletexto editada en 2003 por la Asociación Española de Normalización y Certificación, AENoR. ${ }^{\text {Io }}$ En su elaboración han colaborado asociaciones relacionadas con las personas discapacitadas (FIAPAS, ONCE, Con-

8 Artículo 62 Acceso para personas con discapacidades (...) «Para favorecer el acceso de las personas con discapacidad auditiva o visual a los medios de comunicación audiovisual, se impondrán a las entidades que tengan atribuida la gestión directa del servicio público de televisión de titularidad estatal o autonómica y a los titulares de licencia para la difusión de televisión de ámbito nacional y autonómica la obligación de ofrecer una parte significativa de sus contenidos acompañada de sistemas de subtitulado, lenguaje de signos y audiodescripción. El Estado y las Comunidades Autónomas regularan mediante Ley las anteriores obligaciones y establecerán un régimen transitorio para la implantación progresiva de las mismas».

9 Disposición adicional quinta «Facilidades para el acceso de personas con discapacidad en los servicios de televisión bajo competencia del Estado» y Disposición Transitoria Quinta «Facilidades para el acceso de los discapacitados». 
Tabla 2: Calendario de implementación de servicios de accesibilidad en la televisión española. Fuente: borrador de la Ley general del audiovisual.

SERVICIO OPERADORES DE PÚBLICO

\begin{tabular}{|l|l|l|l|l|l|l|l|l|l|l|}
\cline { 2 - 10 } & $\mathbf{2 0 0 6}$ & $\mathbf{2 0 0}$ & $\mathbf{2 0 0} 8$ & $\mathbf{2 0 0 9}$ & $\mathbf{2 0 I 0}$ & $\mathbf{2 0 I I}$ & $\mathbf{2 0 I 2}$ & $\mathbf{2 0 I 3}$ & $\mathbf{2 0 I 4}$ & $\mathbf{2 0 I 5}$ \\
\hline Subtitulado & $40 \%$ & $45 \%$ & $50 \%$ & $55 \%$ & $60 \%$ & $65 \%$ & $70 \%$ & $80 \%$ & $90 \%$ & Iо०\% \\
\hline Lenguaje de signos & I $\%$ & $2 \%$ & $3 \%$ & $4 \%$ & $5 \%$ & $6 \%$ & $7 \%$ & $8 \%$ & $9 \%$ & Iо $\%$ \\
\hline Audiodescripción & I $\%$ & $2 \%$ & $3 \%$ & $4 \%$ & $5 \%$ & $6 \%$ & $7 \%$ & $8 \%$ & $9 \%$ & Iо $\%$ \\
\hline
\end{tabular}

TITULARES DE LICENCIA ESTATAL

\begin{tabular}{|l|l|l|l|l|l|l|l|l|l|l|}
\cline { 2 - 10 } & $\mathbf{2 0 0 6}$ & $\mathbf{2 0 0 7}$ & $\mathbf{2 0 0 8}$ & $\mathbf{2 0 0 9}$ & $\mathbf{2 0 I O}$ & $\mathbf{2 O I I}$ & $\mathbf{2 0 I 2}$ & $\mathbf{2 0 I 3}$ & $\mathbf{2 0 I 4}$ & $\mathbf{2 0 I 5}$ \\
\hline Subtitulado & $35 \%$ & $40 \%$ & $45 \%$ & $50 \%$ & $55 \%$ & $60 \%$ & $65 \%$ & $70 \%$ & $75 \%$ & $80 \%$ \\
\hline Lenguaje de signos & $\mathrm{I} \%$ & $\mathrm{I}, 5 \%$ & $2 \%$ & $2,5 \%$ & $3 \%$ & $3,5 \%$ & $4 \%$ & $4,5 \%$ & $4,5 \%$ & $5 \%$ \\
\hline Audiodescripción & $\mathrm{I} \%$ & $\mathrm{I}, 5 \%$ & $2 \%$ & $2,5 \%$ & $3 \%$ & $3,5 \%$ & $4 \%$ & $4,5 \%$ & $4,5 \%$ & $5 \%$ \\
\hline
\end{tabular}

RESTO DE CANALES DE ÁMBito NACIONAL CON MÁS DEL IO\% DE AUDIENCIA

\begin{tabular}{|l|l|l|l|l|l|l|l|l|l|l|}
\cline { 2 - 11 } & $\mathbf{2 0 0} 6$ & $\mathbf{2 0 0}$ & $\mathbf{2 0 0} 8$ & $\mathbf{2 0 0 9}$ & $\mathbf{2 0 I O}$ & $\mathbf{2 O I I}$ & $\mathbf{2 0 I 2}$ & $\mathbf{2 0 I 3}$ & $\mathbf{2 0 I 4}$ & $\mathbf{2 0 I 5}$ \\
\hline Subtitulado & $\mathrm{I} 5 \%$ & $20 \%$ & $25 \%$ & $30 \%$ & $35 \%$ & $40 \%$ & $45 \%$ & $50 \%$ & $55 \%$ & $60 \%$ \\
\hline Lenguaje de signos & $0,5 \%$ & $0,5 \%$ & $0,5 \%$ & $\mathrm{I} \%$ & $\mathrm{I} \%$ & $\mathrm{I} \%$ & $\mathrm{I}, 5 \%$ & $\mathrm{I}, 5 \%$ & $\mathrm{I}, 5 \%$ & $2 \%$ \\
\hline Audiodescripción & $0,5 \%$ & $0,5 \%$ & $0,5 \%$ & $\mathrm{I} \%$ & $\mathrm{I} \%$ & $\mathrm{I} \%$ & $\mathrm{I}, 5 \%$ & $\mathrm{I}, 5 \%$ & $\mathrm{I}, 5 \%$ & $2 \%$ \\
\hline
\end{tabular}

federación Nacional de Sordos de España, La Asociación de Implantes Cocleares), televisiones públicas, privadas y autonómicas, empresas de subtitulado y profesionales relacionados con estos sectores.

Dos años después, en enero de 2005, se editó

Io AENOR comenzó en 1986 cuando, mediante una Orden Ministerial, quedo reconocida como la única entidad que podía desarrollar tareas de normalización y certificación en España. Posteriormente, mediante un Real Decreto en 1995, la ratificaron como responsable de la elaboración de las normas españolas, conocidas como normas UNE, siglas que responden a Una Norma Española. Las normas son documentos elaborados por consenso entre todas las partes interesadas. En AENOR la segunda norma de accesibilidad a los medios: la norma UNE 153020 Audiodescripción para personas con discapacidad visual. Requisitos para la audiodescripción y elaboración de audioguias. Sus principales beneficiarios son las empresas y profesionales que hacen accesible el material audio-

existen unos órganos técnicos, denominados Comités Técnicos de Normalización (AEN/CTN), que estudian y plantean las necesidades de cada sector y elaboran y aprueban los proyectos de normas que después se publican como normas UNE. En el caso de nuestra norma, el comité técnico que la ha elaborado es el AEN/CTN I53 Ayudas Técnicas para personas con discapacidad. Este comité forma parte de la asociación empresarial FENIN, representante de las empresas en el área sanitaria. 
visual a las personas con deficiencias visuales y su objetivo es guiarlos en la elaboración de guiones audiodescriptivos (Orero, 2005).

Con el objetivo de alcanzar un consenso en la industria para la implantación de la accesibilidad en Tv Digital, el Foro Técnico de la Tv Digital creó en 2004 un grupo de trabajo sobre accesibilidad. Sus principales objetivos eran identificar y evaluar las funcionalidades y necesidades de los diferentes colectivos de personas con discapacidad con respecto a la TV digital, identificar las necesidades de normalización y promover la investigación y los desarrollos tecnológicos. En octubre de 2005, se redactó un documento (Foro Técnico de la Tv Digital, 2005:6) que deberá servir de apoyo y referencia para el desarrollo de productos, servicios y herramientas técnicas para la accesibilidad a la TV digital. Algunos de ellos, como el sps o la $\mathrm{AD}$, que ya habían sido implementados en el entorno analógico, pueden encontrar en la nueva tecnología nuevas perspectivas, más flexibilidad y mayor calidad técnica.

\section{IMPLICACIONES ECONÓMICAS Y OPERATIVAS DE LA ACCESIBILIDAD EN EL SECTOR DE LA RADIODIFUSIÓN}

Para hacer un análisis del coste que puede suponer para una cadena de televisión subtitular el I00\% de la programación, hemos tomado como referencia el coste que aparece reflejado en el informe de viabilidad del Centro Español de Subtitulado y Audiodescripción (cEsyA) elaborado por el Real Patronato sobre Discapacidad (2005: 169):

En términos generales, las tarifas de subtitulación oscilan en nuestro país entre los $4 €$ y los $6 €$ el minuto grabado, y los $9 €$ el falso directo (programas emitidos con un pequeño retardo). Esto se traduciría en una media de entre 240 a $360 €$ la hora subtitulada, 6oo€ en el caso de los programas más caros.

Si toda la programación se tuviera que subtitular de nuevo y considerando que un año lo componen 8.760 horas, la inversión anual necesaria estaría por encima de los 2.500.000 euros por operador. Por supuesto que la creatividad en la organización del trabajo puede reducir esta cifra con una gestión inteligente de los recursos disponibles y con la circulación eficiente de materiales subtitulados, pero en cualquier caso puede resultar un coste elevado para algunos radiodifusores y sobre todo para los pequeños canales que están surgiendo con el proceso de migración digital.

Con respecto a los costes de la AD no existe todavía en España un mercado maduro y competitivo que haya fijado unas tarifas homogéneas. El cesya estima un coste medio entorno a 1500 euros por película en el caso de las obras cinematográficas y 800 euros por hora para los contenidos televisivos. A este coste habría que sumar el ancho de banda de transmisión de un canal de audio. Pero no todos los contenidos de televisión son susceptibles de ser audiodescritos. Cuando la densidad del diálogo no deja espacios de silencio, no es posible realizar este servicio de apoyo. Por otra parte, en programas como los informativos, debates o concursos, una realización cuidadosa puede conseguir que las personas con discapacidad visual sigan perfectamente el desarrollo del programa. En el documento del Foro de la Tv digital (2005:I8) se considera que «para que el discapacitado visual disfrute de un $95 \%$ de la programación sólo es necesario audiodescribir el ıoo\% de las películas, series y documentales emitidos, lo que representa no más de un $35 \%$ de la programación total.»

En el Reino Unido y en Estados Unidos, el número de horas de emisión con $\mathrm{AD}$ a que obliga el regulador es muy inferior al del sps y, como 
hemos visto, el desarrollo reglamentario que se está preparando en España sigue esta tendencia.

Con respecto a las implicaciones que puede 40 tener la accesibilidad en la organización de los radiodifusores, lo primero que debemos plantear es la necesidad de concienciar a los trabajadores de las plantillas de las televisiones. La formación es la primera acción que hay que emprender para conseguir que, cada uno desde su especialización profesional, tenga en consideración la diversidad sensorial de la audiencia. También es necesaria la incorporación de personal especializado en accesibilidad para gestionar y producir los servicios. Incentivar la circulación de materiales y gestionar correctamente los derechos de explotación y propiedad intelectual son elementos cruciales para la racionalización de las inversiones. Actualmente, cada emisora produce SPS y AD para sus necesidades de emisión, pero el intercambio de ficheros entre las diferentes ventanas de explotación no es suficientemente fluido. Se deberían producir las películas de cine accesibles para su estreno en salas y, a partir de ese momento, distribuirlas siempre junto con SPS y AD por las siguientes ventanas: venta y alquiler en soporte DVD, distribución por los diferentes sistemas de televisión de pago y por último la difusión por canales de televisión en abierto. Desgraciadamente, esto no ocurre frecuentemente y se subtitula varias veces el mismo contenido para el mismo mercado.

\section{EL CENTRO ESPAÑOL DE SUBTITULAdo Y AUDIODESCRIPCIÓN (CESYA)}

El cesya es una iniciativa que surge a finales del año 2005, como un proyecto dependiente del Ministerio de Trabajo y Asuntos Sociales, a través del Real Patronato sobre Discapacidad. Cuenta con la colaboración del cERMI y está liderado por la Universidad Carlos III de Madrid por medio del Instituto para la Promoción de la Innovación Pedro Juan de Lastanosa. Se constituye con la misión de impulsar y promocionar la accesibilidad audiovisual en España por medio de SPS y AD. En él confluyen todos los actores implicados y sirve de nexo de unión y diálogo entre todos ellos. Las asociaciones de representación de personas con discapacidad, la industria de la producción/distribución de contenidos, los exhibidores/radiodifusores, la industria de la electrónica de consumo, las universidades y el regulador del sector audiovisual y la accesibilidad encuentran en el cesya un espacio de referencia para la implantación efectiva de la accesibilidad en los medios de comunicación audiovisual.

Uno de los objetivos prioritario del cesya es la creación y gestión de un servicio de base de datos - con reseñas de las obras audiovisuales subtituladas y audiodescritas- permanentemente actualizada y a disposición de los agentes vinculados con el escenario audiovisual y la accesibilidad. El fondo documental, totalmente informatizado, se puede consultar a través de Internet. La finalidad de esta línea de actividad es recoger y referenciar todas las producciones audiovisuales subtituladas y audiodescritas para favorecer la circulación de materiales e impulsar el mercado de subtítulos, la audiodescripción y otros servicios de apoyo a la comunicación (Ruiz et al, 2006).

Otro de los ejes de actuación es diseñar iniciativas de sensibilización al concepto de 1a Accesibilidad Universal para la industria audiovisual y, por extensión, lograr también la sensibilización de la población en general. Así mismo, este centro se plantea ser pionero en la observación en el nivel internacional de la investigación y normalización que tanto en la 
subtitulación como en la audiodescripción se lleve a cabo.

La formación está también en el punto de mira y se realiza un seguimiento de las iniciativas nacionales e internacionales con el objetivo de la homologación de la formación reglada de los profesionales de la accesibilidad audiovisual.

La creación de este centro es un paso necesario para la implantación de unos medios audiovisuales accesibles en España y para avanzar hacia la igualdad de oportunidades y derechos de las personas con algún tipo de discapacidad visual o auditiva.

\section{CONCLUSIONES}

Como hemos podido comprobar, existen distintas iniciativas y proyectos encaminados a favorecer la accesibilidad a los medios audiovisuales en España. Para alcanzar este objetivo es necesario el trabajo coordinado de todos los actores implicados en este proceso: la industria audiovisual, las asociaciones de representación de los usuarios con discapacidad y la administración reguladora. La investigación multidisciplinar y la formación de profesionales son también elementos esenciales para impulsar esta necesaria transformación de los medios de comunicación que se han de adaptar obligatoriamente a la nueva concepción de la accesibilidad que se establece en la Ley de igualdad de oportunidades del 2003 (Ley 51/2003) y en el Plan Nacional del 2003. Las administraciones públicas deben tender a normalizar los entornos haciendo que estos estén pensados y diseñados para hacer frente a las necesidades de todos. En el caso de los medios audiovisuales, el sps y la AD encajan en lo que la ley ha denominado como «ajustes razonables» que facilitan la participación de todos en condiciones de igualdad.
El costo económico de estos ajustes recae en las empresas públicas o privadas responsables de la difusión pública de los contenidos audiovisuales: productores, distribuidores y exhibidores / radiodifusores. El objetivo de que todos los contenidos audiovisuales sean accesibles para todos queda, en la práctica, limitado por la complejidad operativa que esto supone para la industria y por el coste económico que conlleva. Los reguladores del sector tienen que marcar unos calendarios razonables de implantación e idear políticas para incentivar la accesibilidad audiovisual como, por ejemplo, aplicar desgravaciones fiscales o prioridad en la adjudicación de frecuencias para empresas y proyectos de comunicación accesible. También será necesario establecer los mecanismos de control y sanción para las empresas que incumplan las reglas establecidas (Pérez Ugena et al., 2005:22I).

Los medios de titularidad pública deberían marcar el camino y servir de motor para que la industria de producción y distribución de contenidos incorpore los procedimientos necesarios para garantizar la disponibilidad de servicios de apoyo en toda la cadena de distribución (Utray, 2006:254).

Para favorecer el desarrollo de la accesibilidad a los medios se han identificado cinco factores claves: regulación, comunicación, formación, producción y señalización.

En relación a la regulación es fundamental que la administración lleve a cabo sus atribuciones y supervise los procedimientos de funcionamiento. Debería crearse un organismo regulador para que controle tanto la calidad como la cantidad de accesibilidad. Este nuevo organismo regulador, Consejo Español del Audiovisual, debería poder tener una capacidad sancionadora, al tiempo que fomente las buenas prácticas y autorregulación, de esta manera se 
podrían favorecer la concesión de licencias a aquellos radiodifusores que velen por una accesibilidad de calidad. También se debería intentar buscar una posibilidad de beneficios fiscales para aquellos que favorezcan la accesibilidad, ya sean los productores de material audiovisual o los radiodifusores.

Una formación de calidad es, sin lugar a duda, una de las claves para crear una plantilla de profesionales cualificados que produzca materiales audiovisuales accesibles. Es importante continuar con los cursos que se ofrecen desde las universidades y se debería potenciar una colaboración entre la empresa y la universidad para ajustar las necesidades del mercado en la formación universitaria.

No cabe duda de que la manera de potenciar la producción en el futuro es fomentando la cultura de intercambio de materiales con contenidos accesibles dentro de la propia industria del audiovisual. También sería interesante aumentar la participación de los patrocinadores en los programas accesibles.

$Y$ para terminar, es imprescindible crear un sistema de iconos que identifiquen claramente los productos accesibles. Ninguna de las dos normas UNE han sugerido el uso de un icono, sin embargo en la Unión Europea el organismo encargado de estandarizar todos los temas relacionados con la comunicación, European Standards Telecommunication Institute (ETSI), ha presentado, tras una dilatada investigación, la Norma ES 202432 que estará lista en febrero de 2007 en la que se recomienda el uso de los iconos que reproducimos en la figura $\mathrm{r}$ :

Esperamos que la sensibilización social y la promoción de la accesibilidad audiovisual sea una tarea que pueda contribuir a la construcción de una sociedad más consciente de la diversidad de los ciudadanos que la componen.

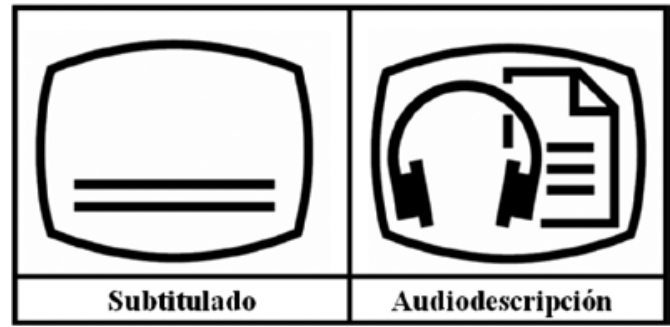

Figura I: Iconos propuestos para el subtitulado y la audiodescricpción en el borrador de norma ETSI ES 202432

RECIBIDO EN DICIEMBRE 2006 ACEPTADO EN ENERO 2007

\section{BIBLIOGRAFÍA}

Aenor (2003). Norma UNE 1530Io: Subtitulado para personas sordas y personas con discapacidad auditiva. Subtitulado a través del teletexto, Madrid: AENOR.

Aenor (2005). Norma UNE 153020: Audiodescripción para personas con discapacidad visual. Requisitos para la audiodescripción y elaboración de audioguías, Madrid: AENOR.

Arandes, J. (2006). «Un día cualquiera» [en línea]. RNEI. 7 de mayo 2006 , <http://www.rtve.es/ rne/audiocast/noes/files/neudc-o60507-tertulia. $\mathrm{mp} 3>$ [Consulta: 20 de diciembre de 2006].

European Standards Telecommunication Institute (2004). «Borrador de norma ETSI ES 202 432» [en línea]. <http://www.etsi.org> [Consulta: 20 de diciembre de 2006].

Fiapas (200I). «Videoteca subtitulada para personas sordas» [en línea]. <http://www.fiapas. es/videot_p.html> [Consulta: 20 de diciembre de 2006].

Foro Técnico de la DVD (2005). «Accesibilidad en Televisión Digital para personas con discapacidad». Documento elaborado por Grupo de Trabajo 5 sobre Accesibilidad del Foro Técnico de la televisión digital. Madrid: Subdirección General de Infraestructuras y Standardativa Técnica. [en línea]. <http://www.televisiondigital.es/Terrestre/Ciudadanos/ComisionSeguimientoTDT/DocumentosAprobadosForoTec- 
nico/gt5accesibilidad.htm> [Consulta: 20 de diciembre de 2006].

Hernández-Bartolomé, A. y Mendiluce-Cabrera, G. (2004). «Audesc: Translating Images into Words for Spanish Visually Impaired People». Meta, 49/2, pp. 264-277.

Matamala, A. (2005). "Live Audio Description in Catalonia». Translating Today, 4, pp. 9-II.

Mateos Miguélez, B. (2005). Audiodescripción: estudio y análisis a través de un fragmento de la película Shrek, Universidade de Vigo: Facultade de Filoloxía e Tradución. Trabajo de investigación inédito.

Méndez Brage, B. (2002). El subtitulado para sordos, Vigo: Facultade de Filoloxía e Traducción. Trabajo de Fin de Carrera inédito.

Navarrete, F. (1997). «Sistema AUDESC: el arte de hablar en imágenes». Integración, 23, pp. 70-75.

once (I997). Programa Audesc. Informe de la Dirección de Cultura de la once, Madrid: ONCE.

Orero, P. (2005). «Audio Description: Professional Recognition, Practice and Standards in Spain». Translation Watch Quarterly, I, pp. 7-I8.

Orero, P. (2007). «Pioneering Audio Description: Jorge Arandes». JosTrans, 7, pp. I90-I94, <www. jostrans.org>.

Orero, P. (en prensa a). «¿Quién hará la audiodescripción comercial en España? El futuro perfil del descriptor», en Jiménez, C. (ed.) La subtitulación para Sordos y la Audiodescripción en España, Granada: Atrio.

Orero, P. (en prensa b). «Audio subtitling: A Possible Solution for Opera Accessibility in Catalonia». Cadernos de Traduçao, Universidad Federal de Salvador de Bahía: Brasil.

Pardina i Mundó, J. (I998). «El futuro de la subtitulación para personas sordas o con pérdidas auditivas $>$. [en línea]. <http://www.terra. es/personal6/932108627/Articulos/arti3-C.htm> [Consulta: 20 de diciembre de 2006].

Pardina i Mundó, J. (2000). «Estudio sobre el Servicio Audiovisual de Subtitulación para personas sordas o con pérdidas auditivas en el mercado televisivo español». Dirección Audiovisual de la CMT. [en línea]. <http://www.cmt. es/cmt/centro_info/publicaciones/pdf/subtitula. pdf> [Consulta: 20 de diciembre de 2006].

Pereira, A. (2005). «El subtitulado para sordos: estado de la cuestión en España». Quaderns. Revista de traducción, I2, pp. I6I-I72.

Pérez-Ugena, Á. y Utray, F. (2005). «Informe sobre accesibilidad en TV digital», en Pérez-Ugena, Á. y Utray, F. (eds.), TV Digital e integración ¿TV para Todos?, Madrid: Dykinson, pp. 175-237

Real Patronato de la Discapacidad (2005). Estudio de viabilidad del Centro Español de Subtitulado (FASE I), [en línea]. <http://www.rpd.es/cesya. html $>$ [Consulta: 20 de diciembre de 2006].

RTVE (2003a). "Control Parlamentario de RTVE, 28 mayo 2003» [en línea]. <http://www.aideka. tv/Serviciosinformativos/Diario\%2ode\%2oses iones\%2028-5-3.pdf> [Consulta: 20 de marzo de 2005].

RTVE (2003b). «Programación 3 septiembre» [en línea]. <http://www.rtve.es/tve/programo/ avan2/tv2so3og.htm> [Consulta: 20 de marzo de 2005].

RTVE (2005). «Programación I4 enero» [en línea]. <http://www.rtve.es/tve/programo/avan 2/ tv2sI4OI.htm> [Consulta: 20 de marzo de 2005].

Ruiz, B. et al. (2006). «El centro Español de Subtitulado y Audiodescripción: estrategias para fomentar la accesibilidad a los medios audiovisuales en España», en Ferreira, A. et al, (eds.), IV Congreso Iberoamericano Sobre Tecnologias de Apoyo para la Discapacidad, vol.2, Vitoria, Brasil: Iberdiscap, pp. 16I-165.

Utray, F. (2005). «La emisión de servicios de apoyo para personas con discapacidad en televisión digital», en Peinado, F. (ed.), La Radio y la Televisión en la Europa Digital, Madrid: UPM, pp. 365-367.

Utray, F. (2006). «Situación actual de la accesibilidad a la TV en España», en Ferreira, A., Frizera Neto, A. y Freire Bastos Filhio, T. (eds), IV Congreso Iberoamericano Sobre Tecnologias de Apoyo para la Discapacidad, vol.2, Vitoria, Brasil: Iberdiscap, pp. 251-255.

Vidal, A. (2004). «La audiodescripción: una herramienta de ayuda para los ciegos». Integración. Revista de la Asociación de Implantados Cocleares, 32, pp. 30-31. 